\title{
Saúde bucal na velhice: \\ percepção dos idosos, Goiânia, 2005
}

\author{
Oral health in old age: \\ elderly’s perceptions, Goiânia, 2005
}

Sandra Cristina Guimarães Bahia Reis ${ }^{1}$

Vânia Cristina Marcelo 2

\footnotetext{
1 Escola de Saúde Pública Cândido Santiago da Secretaria Estadual do Estado de Goiás. Rua 26 s/n, Santo Antonio, 74853-070, Goiânia GO. sandrabahia@uol.com.br 2 Faculdade de Odontologia da UFG.
}

\begin{abstract}
This study was carried out in order to acquire knowledge of the elderly's perception as to old age and their oral health. Such awareness enables the unveiling of the attributed values to and the meaning of their health as acknowledged by the individuals; it also helps the formulation of policy and programs aiming this group. This is a qualitative piece of research, the data collection of which was obtained by means of semi-structured interviews and systematic observation. Thirty elderly citizens, 20 of long-term staying institutions and 10 participants of the third age group, were interviewed. The major results found were: old age is perceived differently among the elderly, with ideas varying from positive to negative characteristics. The perception of oral health is linked to physical, subjective and social aspects.

Key words Elderly, Perception, Oral health, Old age
\end{abstract}

Resumo Este estudo foi realizado com o objetivo de conhecer a percepção de idosos quanto à velhice e à sua saúde bucal. Esse conhecimento possibilita o desvelar dos valores atribuídos e o significado conferido pelos indivíduos à sua saúde, subsidiando a formulação de políticas e a estruturação de programas para esse grupo populacional. Trata-se de uma pesquisa qualitativa, cuja coleta dos dados se deu através de entrevistas semi-estruturadas e da observação sistemática. Foram entrevistados 30 idosos, 20 de instituições de longa permanência e 10 participantes de grupos de terceira idade. Os principais resultados encontrados foram: a velhice é percebida de maneira diversa entre os idosos, existindo idéias positivas e negativas. A percepção da saúde bucal está ligada a aspectos físicos, subjetivos e sociais.

Palavras-chave Idoso, Percepção, Saúde bucal, Velhice 


\section{Introdução}

A velhice é um tema que tem despertado a atenção pelo aumento da proporção de idosos na população, fenômeno comum a diversos países, tanto os do primeiro mundo como aqueles em desenvolvimento. Esse aumento na longevidade é um ganho que as civilizações moderna e contemporânea têm proporcionado ao homem.

Existem algumas instituições sociais que prestam assistência a idosos, podendo ser organizadas nas formas de: internatos - nos quais o idoso mora por tempo determinado ou não; hospitais-dia - onde os idosos passam o dia e dormem em casa; e casas-lares - que são famílias que abrigam os idosos e recebem remuneração pelo serviço prestado ${ }^{1}$.

A saúde do idoso demanda ações da família e dos serviços de saúde, privados e públicos. Pesquisa do Núcleo de Estudos em Saúde Pública e Envelhecimento (Nespe), do Ministério da Saúde, aponta que $73 \%$ dos idosos brasileiros dependem exclusivamente do sistema público de saúde. Considerando que os investimentos direcionados a essa área são historicamente insuficientes e os baixos rendimentos desses idosos para sua sobrevivência, configura-se uma situação de alta complexidade². Estudo conduzido em Goiânia com equipes do Programa de Saúde da Família (PSF) verificou que os idosos, em sua maioria, possuíam rendimentos inferiores a um salário mínimo e eram analfabetos ${ }^{3}$.

As necessidades odontológicas de idosos são importantes e amplas. Dados epidemiológicos desse grupo populacional podem mostrar a história de vida-saúde e o tipo de atenção recebida em todas as fases de vida. Esses indivíduos apresentam, em geral, um grande número de dentes perdidos e muitos casos em que há necessidade de reabilitações.

Os profissionais de saúde se deparam, além do grande acúmulo de carências, com uma insuficiente rede de serviços para reverter essa realidade. Acrescenta-se ainda a dificuldade de acesso dos idosos aos serviços de saúde, em função da pobreza material de um largo percentual desse grupo, revelada por aspectos que vão desde a falta de condução para ir ao posto de saúde até a falta de dinheiro para comprar as medicações prescritas 4 .

O diagnóstico das condições de saúde/doença de grupos populacionais tem sido tradicionalmente realizado apenas através de indi- cadores numéricos, e a determinação das necessidades de saúde apenas do ponto de vista normativo. Esta postura ignora aspectos sociocomportamentais importantes, que precisam ser considerados na avaliação de condições de saúde. Faz-se, então, necessária a inclusão da percepção da saúde em estudos, pois esse conhecimento possibilita o desvelar dos valores atribuídos e o significado conferido pelas pessoas à sua saúde. Estudos de autopercepção em saúde permitem a participação efetiva da comunidade na formulação de decisões políticas e sociais, incluindo a saúde bucal, além de tornar possível a abordagem mais efetiva dos indivíduos pelos profissionais de saúde 5 .

Assim, o objetivo deste estudo é conhecer a percepção dos idosos quanto à velhice e quanto à sua saúde bucal.

\section{Revisão da literatura}

A Constituição Brasileira, na Seção II, Artigo 196, garante acesso universal a todas as ações de saúde ao afirmar: A saúde é direito de todos e dever do Estado, garantido mediante políticas sociais e econômicas que visem à redução do risco de doença e de outros agravos e ao acesso universal e igualitário às ações e serviços para sua promoção, proteção e recuperação ${ }^{6}$.

A Organização Mundial de Saúde (OMS) define saúde como: Um estado de completo bemestar físico, mental e social, e não só a ausência de doença ou de enfermidades 7 . Definição que tem gerado inúmeras críticas por não possibilitar uma compreensão clara do que seja "completo bem-estar" e por transmitir a noção de que saúde é algo tão grande que passa a ser inatingível.

Os conceitos de saúde e doença são abstratos e difíceis de definir, pois se referem a eventos complexos e multidimensionais, que não são bem demarcados e têm significados que variam de acordo com o contexto vivido pelo indivíduo. O pensamento hegemônico sobre saúde e doença está estruturado numa visão negativa da vinculação desses dois estados, e as raízes filosóficas desse pensamento estão ancoradas na idéia de dualidade entre corpo e mente, em que o corpo é visto como uma máquina, abordando-se apenas o aspecto biológico do processo 8 .

O conceito de saúde bucal é tratado como algo anômalo, invariavelmente aparecendo em pesquisas, porém sem que seja explicitado. Pa- 
ra a odontologia, pode-se pensar neste conceito como uma condição do indivíduo cuja dentição lhe permita desenvolver a sua tarefa social ${ }^{8}$.

O conceito de saúde bucal é uma abstração útil e se configura como uma designação didática, pois não pode subsistir como saúde parcial, sendo um termo que serve para identificar objetivos parciais em programas de saúde 9 .

Saúde bucal aparece na 1a Conferência Nacional de Saúde Bucal (1986) como: Parte integrante e inseparável da saúde geral do indivíduo, e está diretamente relacionada às condições de alimentação, moradia, trabalho, renda, meio ambiente, transporte, lazer, liberdade, acesso e posse da terra, acesso aos serviços de saúde e a informação ${ }^{10}$.

Quanto a dados epidemiológicos em saúde bucal de idosos, uma revisão bibliográfica retrata índices altos de ataque de cárie e de doenças periodontais 11 .

O Ministério da Saúde desenvolveu, em parceria com outras instituições, o levantamento epidemiológico "Condições de saúde bucal da população brasileira - Projeto SB Brasil, 2003", que utilizou perguntas fechadas para determinar a autopercepção da saúde bucal de idosos brasileiros. Os resultados obtidos foram: $45,99 \%$ dos idosos de 65 a 74 anos consideram sua saúde bucal boa; $27,48 \%$ consideram-na regular; $8,01 \%$, ruim; e 2,46\% não sabem ${ }^{12}$.

Estudos epidemiológicos são imprescindíveis para a identificação dos problemas da população, mas precisam ser associados às pesquisas que investigam os significados de como as pessoas percebem seus problemas de saúde e se posicionam diante deles, pois permitem identificar valores sociais, culturais e econômicos que influenciam na sua qualidade de vida 13 .

$\mathrm{Na}$ abordagem dos estudos de autopercepção em saúde bucal, alguns índices específicos são encontrados. Destaca-se o GOHAI (Geriatric Health Oral Assessment Index), índice composto de 12 itens que possibilitam a obtenção de informações envolvendo aspectos ligados à mastigação, ao discurso, à fonação, e outros 14 .

Idoso na Política Nacional do Idoso é o indivíduo com 60 anos ou mais de vida15. Já a atitude da sociedade em relação aos velhos é ambígua, geralmente não encarando a velhice como uma fase marcada. O momento em que começa a velhice é mal definido, varia de acordo com as sociedades, as épocas e lugares. A velhice é uma realidade de difícil definição, é um fe- nômeno biológico, acarreta conseqüências psicológicas, e é associada ao aparecimento de certos comportamentos considerados próprios da velhice. Tem uma dimensão existencial, pois modifica o relacionamento do indivíduo com o tempo e, em conseqüência, o seu relacionamento com o mundo e com sua própria história16.

A percepção da velhice é um fenômeno pessoal. A referência do ser idoso é no outro, isto é, aquele que sou para os outros, a velhice é reconhecida mais claramente para os outros, é um processo que o próprio sujeito só enxerga na coletividade. Isso distingue a velhice da doença que, ao chegar, é sentida e o corpo se defende. Já o envelhecimento não tem sintomasi6.

Autopercepção em saúde é a interpretação que a pessoa faz de suas experiências de saúde e estados precários de saúde no contexto da vida diária. Este julgamento se baseia, em geral, na informação e nos conhecimentos disponiveis, modificados pela experiência prévia e pelas normas sociais e culturais 5 .

A percepção em saúde bucal está associada aos aspectos físicos e subjetivos relacionados à boca, e é influenciada por fatores sociais e econômicos, pela idade, sexo e classe social do indivíduo ${ }^{17}$. Para muitas patologias, a necessidade percebida depende das crenças e do conhecimento da pessoa afetada, e também dos critérios de valor atribuídos à saúde perdida. Assim, a avaliação da saúde por pessoas leigas difere da que é feita por profissionais, pois os conceitos de má saúde e de doença são determinados por valores culturais 18 .

A percepção dos idosos sobre a velhice foi estudada por diversos autores 13, 16, 19, 20, 21, 22, 23, 24, retratando imagens positivas e negativas sobre a velhice. Também a autopercepção da saúde bucal tem sido bastante pesquisada 17,25 , $26,27,28,29$, sendo percebida de modo diferente por indivíduos, sociedades e gerações, mostrando a diversidade de experiências e valores dos idosos.

\section{Método}

A abordagem do presente estudo é qualitativa, utilizando-se da técnica de entrevistas semi-estruturadas e da observação sistemática. A metodologia qualitativa favorece a identificação de detalhes, de crenças e valores, e tem a capacidade de fazer emergir aspectos novos, além de estar na perspectiva do sujeito ${ }^{30}$. 
A pesquisa foi realizada em duas instituições de longa permanência da cidade de Goiânia. Ambas de regime aberto, forma de funcionamento em que o ir-e-vir do idoso entre a instituição e o ambiente externo é permitido sem a necessidade de acompanhante. Abrangeu também dois grupos de terceira idade cadastrados na Fundação Municipal de Desenvolvimento Comunitário da Prefeitura $\mathrm{Mu}-$ nicipal de Goiânia. Nesses grupos, os idosos participam de diversas atividades educativas $\mathrm{e}$ de lazer, permanecendo no seu contexto familiar.

Este estudo foi submetido ao comitê de ética do Hospital das Clínicas da UFG, com o protocolo no 019/05, tendo sido aprovado.

As instituições de longa permanência pesquisadas se caracterizam por abrigarem idosos independentes e parcialmente dependentes sem comprometimento cognitivo 31 . Os grupos de terceira idade pesquisados se desenvolvem, respectivamente, no salão social de uma igreja e no auditório de um centro de saúde da Secretaria Municipal de Saúde.

Foram entrevistados 30 idosos de ambos os sexos e com a idade variando de 60 a 90 anos. O número de entrevistas foi finalizado quando as categorias do discurso se repetiam, e chegou-se ao esgotamento ${ }^{32}$. Os dados foram examinados com o uso da análise de conteúdo, orientada pela criação de categorias, tendo o tema como regra de recorte ${ }^{32,33}$.

\section{Resultados e discussão}

Nas entrevistas e na observação sistemática, os idosos expuseram o que pensam e sentem sobre sua velhice e saúde bucal. Foram entrevistados 26 mulheres $(86,7 \%)$ e 4 homens $(13,3 \%)$. A maioria dos idosos institucionalizados pertence à faixa etária de 70 a 80 anos $(50 \%)$. Ao contrário dos idosos dos grupos, em que a maioria está abaixo de 69 anos (80\%).

\section{Percepção da velhice}

As perguntas iniciavam-se com: "Como é a experiência da velhice para o sr.(a)?” Os relatos obtidos nas entrevistas apresentaram-se heterogêneos quanto à percepção da velhice, não existindo uma visão única do que é essa experiência. Na observação sistemática executada pela pesquisadora, viu-se que a utilização do termo "velhice" no enunciado da pergunta ocasionou reações diversas nos idosos, principalmente nos institucionalizados. Expressões faciais denotando tristeza e desânimo surgiram, aparecendo até a negação da velhice pelo fato de a vivência não se enquadrar no estereótipo social do que é essa fase da vida. Vários autores produziram trabalhos que podem explicar essas reações ao termo velhice $34,35,36$.

Quanto à percepção da velhice dos idosos “institucionalizados", encontraram-se duas visões distintas. Um grupo com uma imagem positiva e outro com uma imagem negativa da velhice. O quadro 1 retrata as idéias associadas pelos idosos.

Quatro aspectos aparecem para justificar a imagem positiva da velhice. O primeiro deles foi a existência da aposentadoria. Uma idosa assim fala: É boa né, pelo menos depois que eu vim pra cá, é tudo bom, a gente não paga luz nem aluguel, não paga água. A aposentadoria e a pensão do meu marido dá pra gente comer e o governo ainda dá a cesta básica, 45 real pra nós (Entrevistada no 2).

A aposentadoria se caracteriza por ser a saída do mundo do trabalho e a entrada no mundo doméstico, pela passagem de um mundo de poder para um mundo onde o poder está nas mãos de outros 37 , e simboliza para alguns a perda de um papel social fundamental - o de indivíduos produtivos ${ }^{34}$.

A fala dos idosos do presente estudo contrasta com as visões apresentadas pelos autores mencionados acima. Essa visão dos idosos em relação à aposentadoria pode ser o resultado de

\begin{tabular}{ll}
\hline $\begin{array}{ll}\text { Quadro 1 } \\
\text { Percepção da velhice dos idosos institucionalizados, }\end{array}$ \\
\hline Grupo com imagnia, GO, 2004. \\
\hline Aposentadoria & Grupo com imagem negativa \\
Experiência adquirida & Dependência \\
Longevidade & Fracasso \\
Melhor que na mocidade & Perda de capacidade física \\
\hline
\end{tabular}


vidas que enfrentaram tantas dificuldades e incertezas quanto ao mínimo necessário para a sobrevivência, tanto na juventude como na maturidade, que a aquisição de um salário certo ocasiona uma existência com mais segurança.

Quanto à visão de ser a velhice uma época melhor do que a mocidade, uma idosa relata: Eu tô muito bem na velhice, graças a Deus, nessa idade que eu tô. Eu faço crochê sem óculos, eu costuro sem óculos, eu dô entrevistas, eu faço propaganda, aquela propaganda daqui foi eu que fiz, foi eu que fiz, eu tenho medalha de natação, eu tenho troféu, eu tenho tudo, tenho duas medalhas e um troféu (Entrevistada no 7).

Essa visão positiva da velhice se mostra associada à capacidade de realizar diversas atividades, incluindo realizações prazerosas. Os preditores de um envelhecimento saudável são: realização de atividades físicas, atividades cognitivas, manutenção de contatos sociais e evitar doenças ${ }^{38}$.

No grupo com imagem negativa, aparecem também quatro imagens associadas à velhice, sendo a primeira delas a dependência. A fala que traduz esta idéia é a seguinte: [...] olha eu sou muito triste[...] da velhice não gosto muito não. Quando eu era jovem eu não tinha barreira na minha frente, sabe! Eu podia resolver tudo né! [...] não precisava de ninguém tá me pegando, tá me ajudando. Hoje eu tenho dificuldades de ir até na loja comprar um pano [...] (Entrevistada no 8 ).

O processo de envelhecimento se caracteriza por provocar no indivíduo alterações morfológicas, funcionais e psicológicas, diminuindo a sua capacidade de adaptação a mudanças no seu meio ambiente. Incapacidades surgem neste processo.

Nos grupos de "terceira idade" visitados, a maioria dos participantes é do sexo feminino.

As imagens associadas à velhice desse grupo se mostram mais homogêneas do que a dos idosos institucionalizados, havendo a tendência para uma imagem positiva. As idéias associadas à velhice são descritas no quadro 2 .

Quanto a ser a velhice uma experiência boa, o depoimento de uma idosa é: Ah! Eu vô te falar uma coisa! A velhice é uma coisa boa, eu me sinto bem [...] (Entrevistada no 5).

Estudos demonstram que, em geral, os idosos mantêm uma visão positiva de si mesmos, apesar das tensões e dificuldades inerentes ao envelhecimento. Isto se dá em razão das experiências de sucessos e fracassos ao longo da vida, e dos ajustamentos que tiveram que ser fei- tos no passado e que são realizados nessa etapa da vida também 39 .

A conotação da boa velhice, livre das obrigações cotidianas, e de ser esta a fase de aproveitar a vida, de brincar, aprender e ensinar, e não a de exclusão social, aparece também associada à velhice.

A imagem da velhice associada a perdas é apresentada; um dos depoimentos é o seguinte: [...] na perca do meu esposo, eu fiquei numa situação precária mesmo, eu agradeço a Fulana aqui do posto, viu. Não me conformo, eu sei que tô errada, mas, dali pra frente eu fiquei doente, tudo ruim, eu não durmo que presta, eu acordo com a boca cheia, tomo remédio, é na marra que eu durmo (Entrevistada no 15).

No aspecto social, os problemas mais freqüentes dos idosos têm sido a perda de papéis, a falta de recursos financeiros, as mudanças na família e a diminuição dos contatos sociais 40 .

\section{Percepção dos idosos \\ quanto à saúde bucal}

As perguntas referentes à saúde bucal iniciaram com: Como está sua saúde bucal hoje? Qual a importância da boca para se ter saúde geral? O que significa para o senhor(a) ter uma boa saúde bucal?

Nos depoimentos colhidos, foi percebida nos idosos uma certa dificuldade para falar sobre saúde bucal isoladamente. Fatos ligados à saúde geral, a dores e incômodos no corpo, eram relatados primeiro e, após estas explicações, surgiam os aspectos ligados à boca. Inicialmente, os idosos se reportavam à sua vida,

\begin{tabular}{lc}
\hline Quadro 2 \\
$\begin{array}{l}\text { Percepção da velhice dos idosos de grupos } \\
\text { de terceira idade, Goiânia, 2004. }\end{array}$ \\
\hline Idéias Associadas & Imagem \\
\hline Perdas & - \\
Negação da velhice & - \\
Experiência boa & + \\
Fase de aprender coisas & + \\
novas, de ensinar e de brincar & \\
Tempo de atividades prazerosas & + \\
\hline Época de mais liberdade & + \\
Longevidade & + \\
Alegria de viver & + \\
Boa mesmo na presença de doenças & + \\
\hline Contatos humanos & + \\
\hline
\end{tabular}


à velhice e aos aspectos ligados à saúde geral. A saúde bucal não foi percebida separada da saúde geral.

Várias imagens surgiram associadas à saúde bucal. O quadro 3 as descreve.

Quanto aos idosos "institucionalizados", as idéias associadas à saúde bucal foram diversas, aparecendo imagens positivas e negativas.

Para um idoso que associa a saúde bucal à ausência/presença de dores, o depoimento foi o seguinte: Tá boa, né? Não tem problema nenhum não, dente bom, não to sintindo nada (D. $\mathrm{G}, 77$ anos). Um outro relato associado à ausência de doenças é descrito: A saúde tá boa, os dentes são bons, não machuca né, não tem doença nenhuma na gengiva [...] (Entrevistada no 6).

A presença de saúde bucal é associada por alguns idosos à realização de consultas ao profissional. Uma fala é a seguinte: Tá ótima! Estou vindo do dentista, o dentista meu, é antigo, antiguíssimo, hoje ele tá bem de vida, então ontem eu perguntei pra ele assim: "Dr Fulano? Como eu vou pagar o senhor?” Eu vou lá toda vida, ele foi assim comigo [...] eu entro, sento, ele nunca fez ficha pra mim, porque agora é outra secretária, é muito chique [...] (Entrevistada no 8).

A odontologia traz, arraigada nela, o conceito de tratar as doenças bucais e o estigma do cirurgião-dentista como aquele que providencia saúde através do tratamento das conseqüências das doenças. Há uma grande diferen- ça entre essa visão e a da odontologia que promove saúde, que objetiva sua atuação não apenas após o aparecimento de doenças, mas sim centrada na saúde 4 .

Os idosos se referem também à associação da saúde bucal com a estética. A fala de uma idosa é a seguinte: Na boca? Eu acho assim ó! Que é muito importante é o cabelo e os dentes [...] meu cabelo está horrível eu tô usando até um arquinho [...]. Eu não quero fazer permanente agora porque em janeiro eu vou pra São Paulo, se eu fizer agora ai [...] quando chegar lá não tem mais nada, e aí é tudo caro (Entrevistada no 8).

Observa-se, no relato, uma desvalorização de outros aspectos da saúde bucal, com a atribuição de valor apenas relacionada à aparência, associada, por exemplo, à estética capilar, a uma parte do corpo que não apresenta função fisiológica muito clara.

A preocupação com a aparência do corpo é um fator relevante nas relações humanas. $\mathrm{O}$ significado estético dos dentes é um fato ligado ao homem desde os seus primórdios ${ }^{41}$. Achados arqueológicos indicam a presença de lesões de cárie, doenças periodontais e perdas dentais em múmias pesquisadas, como também a utilização de meios corretivos para estes eventos, tais como: fixação de dentes, incrustações de pedras e uso de pinturas e limagem nos dentes.

A higiene bucal aparece também como um sinalizador da saúde bucal. A sua presença é

Quadro 3

Percepção da saúde bucal dos idosos, Goiânia, 2004.

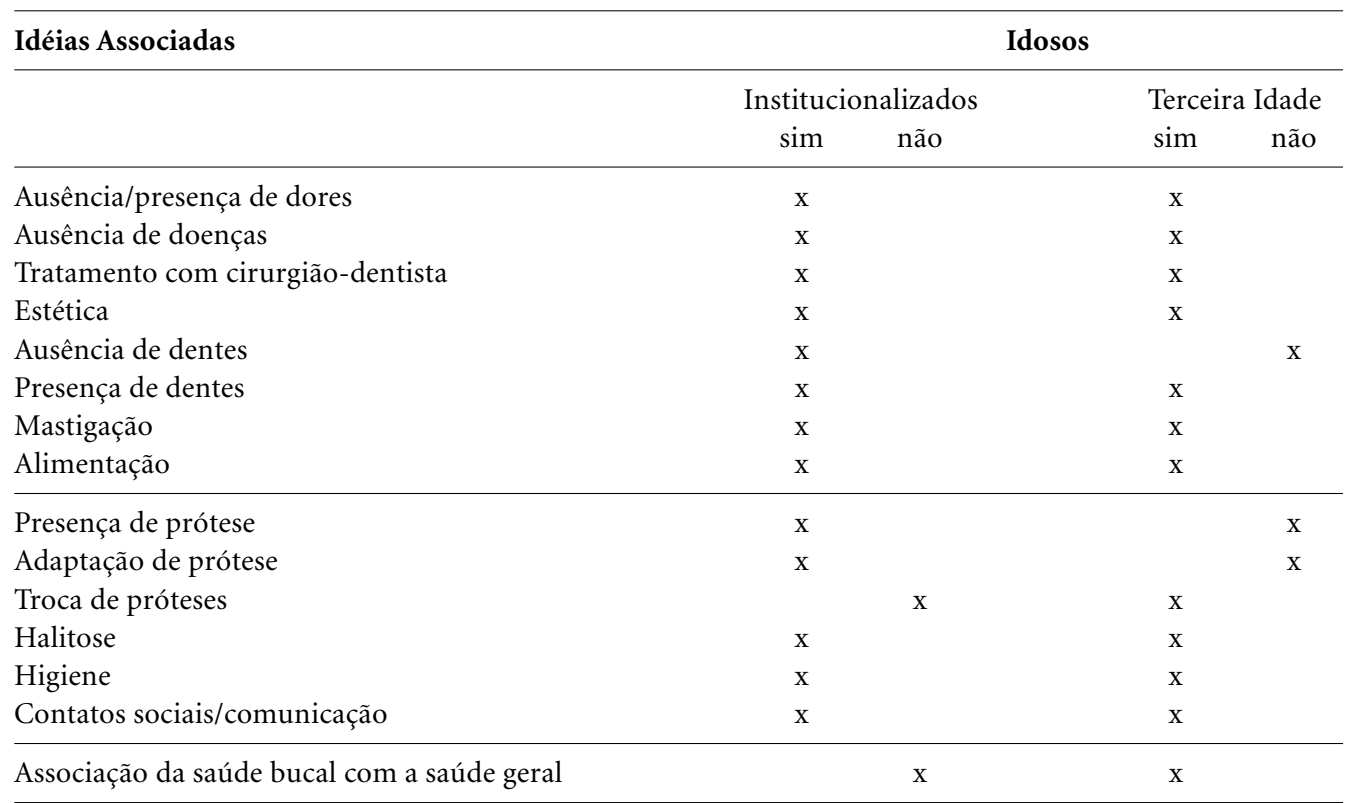


enfatizada nas falas de alguns idosos: Tem que ter higiene né, muita higiene e saber zelar, prótes é muito bom, mas tem que saber zelar dele, limpar, saber tirar, escova, vê aonde tem algum arrepio, alguma coisa, é muito importante né, sabe é muito mais fácil de zelar do que os dente natural, pois a gente tira e vê e limpa aonde é que está, os cantinhos, pode até pegá uma coisa assime rapá. Um dia eu comi tanta pitanga que empretejou meu dente aqui ó, nossa o que tira isso? Ela falou, põe e faça isso assim, eu falei assim o meu Deus do céu, ai eu tirei, olha tem umas manchinhas, umas brechinhas. Entrou dentro do [...] uso escova de roupa [...], mas gente, nunca mais vou comer pitanga, que trem esquisito é esse? (Entrevistada o 1).

Nos depoimentos integrais dos idosos são identificados várias formas, instrumentos e substâncias utilizadas na higienização bucal, entre elas: escova dental; esponja de aço; escova de lavar roupa; raspagem; água sanitária; sabão de coco; e creme dental.

Percebe-se nas falas dos idosos que a preocupação com a higiene é um fato presente nos seus cuidados corporais. Alguns pressupostos de cuidados com a boca e com a prótese são executados a partir de conhecimentos que foram apresentados por profissionais. Outros são associados a procedimentos de limpeza de utensílios gerais.

Quanto aos idosos de grupos de "terceira idade", as idéias associadas à saúde bucal foram também diversas.

O contexto social e familiar desses idosos se diferencia dos idosos institucionalizados. A participação em grupos de terceira idade possibilita contatos sociais prazerosos e de lazer, e também o aprender e compartilhar coisas novas e antigas com pessoas que viveram os mesmos momentos do passado, sem haver uma ruptura de sua história de vida, que é o que acontece com os que tiveram suas casas e hábitos modificados pelo novo espaço de moradia, a instituição.

As percepções quanto à saúde bucal desse grupo de idosos se assemelham bastante ao que foi observado nos idosos institucionalizados, aparecendo quase as mesmas idéias. É importante notar que apesar do contexto social atual ser diferente, suas histórias de vida estão ligadas pelos mesmos fatos sociais que ocorreram no passado.

A associação da saúde bucal à ausência/presença de dores aparece na fala da idosa, assemelhando-se ao que foi percebido pelos idosos institucionalizados. Minha saúde, ah, não é muito boa não, eu tô sentindo uma dor, dói aqui, desde de ontem está assim [...] (Entrevistado no 10).

Sentir dor é uma das principais razões para se temer pela integridade do corpo. Sua presença denota que alguma coisa não vai bem. Em alguns casos, o que aparece primeiro nas diversas disfunções do corpo é a dor e não os sinais que mostram o agravo. A associação da dor à doença é um fato comum.

A vinculação do tratamento odontológico à saúde bucal aparece também entre esses idosos, assim como apareceu nos idosos institucionalizados. Um idoso assim relata: Eu estou precisando de um tratamentinho nos dentes né [...], a boca, tá muito boa não. Eu estou precisando obturar meus dentes e fazer uma limpeza, e isso aí o dinheiro não dá, pra isso hoje! Não dá.[...] É ter os dentes bem tratados, bem cuidados (Entrevistada no 22).

A imagem da odontologia está associada à existência e à manutenção da saúde bucal, assemelhando-se aos relatos dos idosos das instituições.

A estética surge também como um tema vinculado à presença de saúde bucal. No discurso de uma idosa, a associação da estética à saúde bucal aparece. O depoimento é o seguinte: [...] muito feio isso! Por causa da boca, inclusive na minha casa tem espelho, eu fico indo e vindo, sem olhar no espelho, porque eu fico muito triste, meu dente é muito feio, né? [...] a aparência da gente, né? Fica péssima! Eu por exemplo não gosto nem de conversar com pessoas estranhas, é difícil adaptar (Entrevistada no 14).

\section{Conclusões e considerações finais}

Das reflexões e dos dados coletados neste trabalho, algumas conclusões podem ser tiradas.

A feminilização da velhice é uma realidade no grupo pesquisado, pois as mulheres eram a maioria.

O envelhecimento é percebido de maneira heterogênea entre os idosos entrevistados, aparecendo visões positivas e negativas. O estereótipo social do velho dependente, fraco, triste e sozinho, não é compartilhado por todos os entrevistados, nem mesmo por aqueles que vivem em instituição de longa permanência. Houve até casos de idosos que disseram que a velhice era uma época da vida melhor do que a mocidade. 
A saúde bucal é entendida associada à saúde geral, e em alguns depoimentos é percebida como algo além dos aspectos biológicos, extrapolando a clínica odontológica, pois alguns a associam à capacidade de comunicação e aos contatos sociais.

Em relação à saúde bucal, houve mais semelhanças do que discrepâncias entre os idosos de instituições e os de grupos de terceira idade. Este fato pode estar relacionado ao compartilhamento de vida em uma mesma época e cultura do passado, em que valores e conheci-

\section{Colaboradores}

SCGB Reis e VC Marcelo participaram igualmente da concepção, delineamento, análise, interpretação e revisão do artigo.

\section{Referências}

1. Born T, Boechat N. A qualidade dos cuidados ao idoso institucionalizado. In: Freitas EV, Néri AL, Cançado FAX, Gorzoni ML, Rocha SM, organizadores. Tratado de geriatria e gerontologia. Rio de Janeiro: Guanabara Koogan; 2002. p. 768-77.

2. Xavier J. Viver mais e melhor. Radis 2004; 17:8-9.

3. Nakatani AYK, Costa EFA, Teles AS, Silva LB, Rego MAB, Souza ACS, et al. Perfil sócio-demográfico e avaliação de idosos atendidos por uma equipe de saúde da família na periferia de Goiânia, Goiás. Rev Soc Bra Clin Med 2003; 1(5):131-36.

4. Moreira TP, Nuto SAS, Nations MK. Confrontação cultural entre cirurgiões-dentistas e a experiência de usuários de baixa renda em Fortaleza, Ceará. Saúde em Debate 2004; 28(66):58-67.

5. Portillo JC, Paes AM. Autopercepção de qualidade de vida relativa à saúde bucal. Rev Bra Odont Saúde Col 2000; 1(1):75-88.

6. Brasil. Constituição: República Federativa do Brasil. Título VIII, Da ordem social. Seção II, Da saúde. Art. 193. Brasília; 1988.

7. Nutbeam D. Health promotion glossary. In: PAHO, organizador. Health promotion: an anthology. Washington: Pan American Health Organization; 1996; p. 343-59. (PAHO Scientific Publications; 557). mentos sobre saúde bucal foram construídos, influenciando na percepção.

Espera-se que os resultados deste estudo possam fundamentar o planejamento de cursos de capacitação e qualificação de recursos humanos, que pretendam proporcionar maior qualidade na atenção ao idoso, bem como a elaboração de programas preventivos e educativos com maior coerência entre teoria e práti$\mathrm{ca}$ - baseados no diálogo com os maiores interessados na sua saúde, os próprios idosos, e utilizando os seus valores.

\section{Agradecimentos}

Às instituições que apoiaram a realização da pesquisa e aos idosos e idosas que se dispuseram a responder as perguntas das entrevistas
8. Locker D. Concepts of oral health, disease and the quality of life. In: Slade GD. Measuring oral health and quality of life. Chapel Hill: Department of Dental Ecology/University of North Carolina; 1997. p. 11-23.

9. Chaves M. Odontologia social. São Paulo: Artes Médicas; 1986.

10. Brasil. Ministério da Saúde. I Conferência Nacional de Saúde Bucal. Relatório final. Brasília: MS; 1986.

11. Machado FR. Saúde bucal do idoso: aspectos epidemiológicos [monografia]. Goiânia (GO): Faculdade de Enfermagem da Universidade Federal de Goiás; 2001.

12. Brasil. Ministério da Saúde. Secretaria de Atenção à Saúde. Departamento de Atenção Básica. Projeto SB Brasil 2003. Condições de saúde bucal da população brasileira 2002-2003: resultados principais. Brasília: MS; 2003.

13. Uchoa E, Firmo JOA, Lima-Costa. MFF. Envelhecimento e saúde: experiência e construção cultural. In: Minayo MCS, Coimbra CEA, organizadores. Antropologia, saúde e envelhecimento. Rio de Janeiro: Fiocruz; 2002. p. 25-35.

14. Atchinson KA, Dolan TA. Development of geriatric oral health: assessment index. J Dent Educ 1990; 54 (11):680-87. 
15. Brasil. Ministério da Justiça. Secretaria Nacional dos Direitos Humanos. Programa Nacional dos Direitos Humanos. Política Nacional do Idoso. Declaração Universal dos Direitos Humanos. Brasília: MJ; 1998.

16. Beauvoir S. A velhice. Rio de Janeiro: Nova Fronteira; 1990.

17. Silva SRC. Autopercepção das condições de saúde bucal em pessoas com 60 anos e mais de idade [tese]. São Paulo: Faculdade de Saúde Pública da Universidade de São Paulo; 1999.

18. Sheiham.A A determinação de necessidades de tratamento odontológico: uma abordagem social. In: Pinto, VG. Saúde bucal coletiva. São Paulo: Editora Santos; 2000. p. 223-50.

19. Torsch VL, Ma GX. Cross-cultural comparison of health perceptions, concerns and coping strategies among Asian and Pacific Islander American elders. Qual Health Res 2000; 10(4):471-89.

20. Bosi E. Memória e sociedade: lembranças de velhos. São Paulo: Companhia das Letras; 1995.

21. Costa FG Representação social da velhice em idosos participantes de instituições para a terceira idade [dissertação]. Goiânia (GO): Universidade Católica de Goiás; 2001.

22. Luca MMBL. Identidades sociais em produção e envelhecimento: um estudo de caso. In: Simon ORMV, Neri AL, Cachioni M, organizadores. As múltiplas faces da velhice no Brasil. São Paulo: Alínea; 2003. p. 189-210.

23. Heredia VBM, Cortelletti IA, Casara MB. Idoso asilado. Caxias do Sul: Ed. da PUCRS; 2004.

24. Lima-Costa MF, Firmo JOA, Uchoa E. A estrutura da auto-avaliação da saúde entre idosos: projeto Bambuí. Rev Saúde Pública 2004; 389(6):827-34.

25. MacEntee MI. Measuring the impact of oral health in old age: a qualitative reaction to some quantitative views. Gerontology 1996; 13(2):76-81.

26. Wolf SMR. O significado psicológico da perda dos dentes em sujeitos adultos. Rev APCD 1998; 52(4): 307-16.

27. Unfer B, Saliba O. Avaliação do conhecimento popular e práticas cotidianas em saúde bucal. Rev Saúde Pública 2000; 34(2):190-95.

28. Miraschi C, Lamadrid SS. Conocimentos, creencias y conductas en salud oral en adultos mayores de nivel socioeconomico bajo. Zona norte de Santiago. Cuad Med Soc 2000; 41(3):5-13.
29. Organização Pan-Americana de Saúde. O projeto $S A$ BE no município de São Paulo: uma abordagem inicial. Brasília: Opas; 2003.

30. Serapione M. Métodos qualitativos e quantitativos na pesquisa social em saúde: algumas estratégias para a integração. Rev C S Col 2000; 5(1):187-92.

31. Fédération Dentaire Internationale. World Health Organization. Global goals for oral health in the year 2000. Int Dent J 1982; 32:74-7.

32. Minayo MCS. O desafio do conhecimento: pesquisa qualitativa em saúde. 4a ed. São Paulo: Hucitec; 1992.

33. Bardin L. Análise de conteúdo. Portugal: Edições 70; 1977.

34. Peixoto C. Entre o estigma e a compaixão e os termos classificatórios: velho, velhote, idoso, terceira idade. In: Barros, MML, organizadora. Velhice ou terceira idade? Rio de Janeiro: FGV; 2000. p. 69-84.

35. Barros MML. Testemunho de vida: um estudo antropológico de mulheres na velhice. In: Barros MML, organizadora.Velhice ou terceira idade. Rio de Janeiro: FGV; 2000. p. 113-68.

36. Neri AL, Freire AS. Apresentação. Qual é a idade de velhice? In: Neri. AL, Freire AS, organizadores. E por falar em boa velhice. São Paulo: Papirus; 2000. p. 1923.

37. Stucchi D. O curso de vida no contexto da lógica empresarial: juventude, maturidade e produtividade na definição da pré-aposentadoria.In: Barros MML, organizadora. Velhice ou terceira idade. São Paulo: FGV; 2000. p. 35-46.

38. Kiyak HA. Successful aging: implications for oral health. J Public Health Dent 2000; 60(4):276-81.

39. Freire SA. Envelhecimento bem-sucedido e bem-estar psicológico. In: Neri AL, Freire AS, organizadores. E por falar em boa velhice. São Paulo: Papirus; 2000. p. 21-31.

40. Nascimento MCR, Sanches MAS, Dalcin NVE, Gama RGFM, Angélica MPP. Qualidade de vida na terceira idade. In: Paz SF, Goldman SN, Portela A, Arnaut T, organizadores. Envelhecer com cidadania: quem sabe um dia? Rio de Janeiro: ANG-RIO, GBCISS; 2000. p. 121-38.

41. Novaes HMD. Tecnologia e saúde: a construção social da prática odontológica. In: Botazzo C, Freitas SFT, organizadores. Ciências sociais e saúde bucal: questões e perspectivas. São Paulo: Ed. da Unesp; 1998. p. 141-58.

Artigo apresentado em 1ㅇ/07/2005

Aprovado em 1/09/2005

Versão final apresentada em 17/10/2005 